\title{
Verbal Cues to Deceit when Lying through Omitting Information
}

\author{
Sharon Leal \\ Aldert Vrij \\ Haneen Deeb \\ Charlotte Hudson \\ Pasquale Capuozzo \\ Department of Psychology, University of Portsmouth \\ Ronald P. Fisher \\ Department of Psychology, Florida International University
}

Author notes

This work was funded by the Centre for Research and Evidence on Security Threats (ESRC Award: ES/N009614/1)

The data that support the findings of this study are available from the corresponding author upon reasonable request.

Correspondence concerning this article should be addressed to Sharon Leal, Department of Psychology, University of Portsmouth, King Henry Building, King Henry 1 Street, PO1 2DY, Hants, United Kingdom. Email: sharon.leal@port.ac.uk 


\begin{abstract}
Background. Lying through omitting information has been neglected in verbal lie detection research. The task is challenging: Can we decipher from the truthful information a lie teller provides that s/he is hiding something? We expected this to be the case because of lie tellers' inclination to keep their stories simple. We predicted lie tellers to provide fewer details and fewer complications than truth tellers, the latter particularly after exposure to a Model Statement.
\end{abstract}

Method. A total of 44 truth tellers and 41 lie tellers were interviewed about a conversation (debriefing interview) they had taken part in earlier. Lie tellers were asked not to discuss one aspect of that debriefing interview.

Results. Results showed that truth tellers reported more complications than lie tellers after exposure to a Model Statement.

Conclusion. Ideas about future research in lying through omissions are discussed.

\title{
Keywords:
}

- Deception

- Lying through omissions

- Complications 


\section{Verbal Cues to Deceit when Lying through Omitting Information}

Scholars have identified four types of lie (DePaulo, Kashy, Kirkendol, Wyer, \& Epstein, 1996; Leins, Fisher, \& Ross, 2013; Metts, 1989): Outright lies (also called contradictions), exaggerations (also called distortions), embedded lies, and omissions (also called subtle lies). Outright lies are lies in which the information that is conveyed is totally false. Exaggerations are distortions of the truth, such as overstating or understating facts. Embedded lies are lies in which the false information is incorporated in an otherwise truthful story. Omissions are lies by deliberately omitting relevant information. The type of lie is typically not the focus of deception research but in the vast majority of studies participants are asked to provide false information (Vrij, 2008) and this may reflect the occurrence of such lies in real life (DePaulo et al., 1996). Lie tellers in research typically respond to this request by telling embedded lies (Leins, Fisher, \& Ross, 2013). However, practitioners frequently inform us that omissions are very relevant to them, which is why we exclusively focused on omissions in the present experiment.

If evidence is available, omissions could be detected by comparing the statement with the evidence (Granhag \& Hartwig, 2015). For example, a man who truthfully discusses all his activities during a day but deliberately leaves out a brief visit to the shopping mall can be caught out in his lie if CCTV evidence shows that the man did visit the shopping mall that day. However, evidence is not always available to practitioners. In such situations detecting omissions is a challenge in verbal lie detection, because all information an interviewee provides is truthful. The present experiment examined whether someone can decipher from the truthful information an interviewee provides about a past event that $\mathrm{s} / \mathrm{he}$ is hiding something. We are not aware of any previous experiments examining this. We focused on total details and complications, two verbal cues that successfully discriminated truth tellers from lie tellers in deception research to date. 
A popular strategy amongst lie tellers is to keep their stories simple (Hartwig, Granhag, \& Strömwall, 2007). We are not aware of research investigating why this is the case, but at least three reasons sound plausible. First, lying is mentally more taxing than truth telling because lie tellers are multi-tasking (Vrij, Granhag, Mann, \& Leal, 2011; Vrij et al., 2008). Lie tellers are typically less likely than truth tellers to take their credibility for granted (DePaulo et al., 2003). They therefore are more inclined than truth tellers to engage themselves in tasks other than story-telling, including monitoring and controlling their demeanour so that they appear honest to the interviewer (DePaulo \& Kirkendol, 1989) and carefully monitoring the interviewer's reactions to assess whether they appear to be getting away with their lie (Buller \& Burgoon, 1996). Keeping stories simple is one way to cope with the additional strain of multi-tasking. Second, lie tellers cannot rule out that they will be interviewed about an event again. In that case they should not contradict what they have said before. Keeping the initial story simple reduces the likelihood of contradictions occurring in subsequent interviews. Third, lie tellers may avoid providing much information out of fear that it will provide leads to investigators that they have been lying (Granhag \& Hartwig, 2008; Nahari, 2018).

Lie tellers' tendency to keep stories simple may become apparent in the truthful information they provide when omitting information. In the present experiment, we focussed on two verbal cues, details and complications. 'Details' is the most frequently examined verbal cue to date (DePaulo et al., 2003; Vrij, 2008) and 'complications' have shown promising results in recent years (Vrij \& Vrij, 2020). Truth tellers typically report more details than lie tellers (Amado, Arce, Fariña, \& Vilarino, 2016; DePaulo et al., 2013). In the studies examining details to date lie tellers reported untruthful information. It could thus be the case that the effect is caused by lie tellers not providing many details in the untruthful parts of their stories. However, one experiment (not about omissions) suggests that it may be 
possible to decipher from the amount of truthful information provided that an interviewee is hiding something (Vrij, Mann, Jundi, Hillman, \& Hope, 2014). Truth tellers and lie tellers carried out the same activities but did so for different reasons. Lie tellers were requested to hide their malevolent reason and to pretend that they carried out the activities for the same benevolent reason as truth tellers. However, in that interview, interviewees were only asked to recall their activities and no question about the reason was asked. Although truth tellers and lie tellers could therefore both be entirely truthful during the interview, truth tellers reported more details about their activities than lie tellers.

Lie tellers' tendency to keep their stories simple may also be reflected in the number of complications they report. A complication is an occurrence that affects the story-teller and makes a situation more difficult ("Initially we did not see our friend, as he was waiting at a different entrance", Vrij et al., 2020). Adding complications makes the story more complex (Vrij, Leal, \& Fisher, 2018), which goes against a lie teller's strategy to keep their stories simple. Research has shown that truth tellers typically report more complications than lie tellers (Amado et al., 2016). This finding has also been obtained in non-Western samples (Russian, Korean and Hispanic samples; Vrij \& Vrij, 2020) and in interviews with or without an interpreter (Vrij \& Leal, 2020). In the studies examining complications to date lie tellers reported untruthful information. It is thus possible that lie tellers reported fewer complications than truth tellers because they did not add complications in the untruthful parts of their stories. However, one experiment, not about omissions, hinted at the possibility that the truthful information lie tellers report contains fewer complications than truth tellers' account (Jundi, Vrij, Hope, Mann, \& Hillman, 2013). Similar to Vrij et al. (2014), truth tellers and lie tellers went on a mission carrying out the same activities, albeit for different reasons. Lie tellers were told not to reveal the malevolent reason for their mission in a subsequent interview but to pretend they carried out the activities for a benevolent reason. 
However, in that interview, only the activities were discussed and no questions about the reason for these activities were asked. Although truth tellers and lie tellers could thus be entirely truthful when discussing their activities, truth tellers included more complications in their stories than lie tellers.

\section{Model Statement}

When lying through omissions lie tellers, like truth tellers, will report truthful information. Differences between truth tellers and lie tellers are therefore likely to be small. In an attempt to enhance differences between truth tellers and lie tellers we used a two-staged interview as recommended by Vrij, Leal and Fisher (2018): An initial free recall followed by a Model Statement followed by a second free recall. The initial free recall is conventional to begin interviews of both truth tellers and lie tellers and allows veracity differences to manifest without any external guidance. Introducing the Model Statement allows for a second opportunity for differences to occur, and especially in terms of new information (not reported in the initial free narrative).

The Model Statement technique is an interview tool designed to encourage interviewees to provide more information in interview settings (Vrij, Leal, \& Fisher, 2018). A Model Statement is an example of a detailed account unrelated to the topic of the interview (Leal, Vrij, Warmelink, Vernham, \& Fisher, 2015) and raises expectations amongst interviewees about how much information to provide (Ewens et al., 2016). Truth tellers report more complications than lie tellers after being exposed to a Model Statement (Vrij, Leal et al., 2017; Vrij, Leal, Jupe, \& Harvey 2018; Vrij et al., 2020). The information covered in complications is often not about key aspects of the activities that someone describes, and the story can be well understood without reporting the complications (Vrij, Leal, \& Fisher, 2018). Without a Model Statement, truth tellers therefore may not report all the complications they remember, however, listening to a Model Statement encourages them to do so. Since lie 
tellers want to keep their stories simple, they may be reluctant to report complications even after being exposed to a Model Statement.

A Model Statement does not seem to enhance differences between truth tellers and lie tellers in the number of details they provide. A Model Statement raises similar expectations amongst truth tellers and lie tellers how much information to provide (Ewens et al., 2016) and in terms of providing details truth tellers and lie tellers seem to respond to a Model Statement in similar ways (Vrij, Leal, \& Fisher, 2018).

\section{Hypotheses}

In Phase 1 of Interview 2 (before the Model Statement) truth tellers will report more details than lie tellers (Hypothesis 1) and more complications than lie tellers (Hypothesis 2). In Phase 2 (after the Model Statement) truth tellers will report more new complications (complications not reported in Phase 1) than lie tellers (Hypothesis 3).

The hypotheses are pre-registered at https://osf.io/erdwq/?view only=405aef6d7bdc4b9ea91c5d20532214e8

In the pre-registration we mentioned that we would consider two more variables common knowledge details and self-handicapping strategies- if they would occur frequently enough in the statements to be used in the analyses. Consulting the transcripts made us aware that these variables did not occur frequently enough. In Phase 1, prior to the Model Statement, one truth tellers reported two common knowledge details. For lie tellers, five reported one, three reported two and one reported three common knowledge details. One participant (a lie teller) reported using one self-handicapping strategy. In Phase 2, after exposure to the Model Statement, only one participant (a lie teller) reported one new common knowledge detail and three participants (one truth teller and two lie tellers) reported one new self-handicapping strategy. We return to this issue in the Discussion.

\section{Method}




\section{Ethics}

Prior to the research, a favourable ethical review decision was given by the relevant ethics committees of the university and funder.

\section{Participants}

Ninety-two participants were originally recruited but seven were discarded due to misunderstanding the instructions. A total of 85 participants took part, 24 males and 61 females. Their average age was $M=23.95$ years $(S D=9.70)$. Most participants $(n=50)$ reported to be White British; other participants were Black British $(n=4)$, White European ( $n$ $=7)$, Arab $(n=2)$, Asian $(n=12)$, African $(n=6)$ or mixed $(n=4)$.

\section{Procedure}

We designed a deception scenario that, although complicated, is relevant to practitioners. Situations that reflect real life enhance the ecological validity of the findings, which subsequently makes practitioners more receptive to them. Full details of the Procedure are provided in Appendix 1. Below follows an outline of that Procedure.

All interviewees carried out the same mission in which they met two agents, Agent 1 and Agent 2. Immediately after completing the mission, they were interviewed about it in Interview 1. All interviewees were asked four questions about Agent 1. The same four questions were asked about Agent 2 to 41 interviewees and about the experimenter to 44 interviewees.

After Interview 1 the interviewees were told that they would be interviewed again (Interview 2), but this time they would be asked to report all details they remembered from Interview 1. All interviewees were then told that if they have spoken about Agent 2 in Interview 1, they should not have done so. Those who spoke about Agent 2 were informed that they should tell in Interview 2 all that was discussed in Interview 1 but to leave out what they had said about Agent 2. The interviewees who were not asked about Agent 2 in 
Interview 1 could thus tell the truth in Interview 2 and became the truth tellers in the experiment. The interviewees who were asked about Agent 2 in Interview 1 had to omit this information in Interview 2 and thus became the lie tellers in the experiment.

Interviewed by a different interviewer in Interview 2, participants were first asked to freely recall all details they remembered from Interview 1 . This was followed by a Model Statement after which participants were asked to recall again all details they remembered from Interview 1. The information they provided about Agent 1, the interviewer and the interview setting were used for hypotheses-testing; the information provided about Agent 2 and the experimenter served as a manipulation check.

By not asking truth tellers in Interview 1 about Agent 2, we achieved that they did not have to omit information in Interview 2 when instructed not to reveal what had been discussed in Interview 1 about Agent 2. By asking truth tellers in Interview 1 the same four questions about the experimenter instead, we made the Interview 1 very similar for truth tellers and lie tellers and, as a result, equally mentally taxing for truth tellers and lie tellers to remember what was asked in Interview 1.

Participants completed a pre-interview questionnaire before Interview 2 and a postinterview questionnaire after Interview 2. The pre-interview questionnaire examined thoroughness of preparation, perception of preparation time and motivation. The postinterview questionnaire measured rapport with the interviewer; likelihood of having to write a statement, the extent to which they paid attention to the content of the Model Statement and the extent to which they focused on the core (defined as very relevant) details of the mission.

\section{Coding}

One coder, blind to the Veracity condition, was taught the coding scheme by the first author who has more than ten years of experience in coding detail. A detail is defined as a non-redundant unit of information. For example, the following statement has 14 details: The 
lady sat on the chair opposite. She started the $\underline{\text { interview }}$ by recording it and she asked me about what I did on the mission and where I met up with the agent. In Phase 2 of Interview 2, only new details were coded. A second coder coded a random sample of 20 transcripts. Interrater reliability between the two coders, using the two-way random effects model measuring consistency, was excellent (Single Measures ICC $=.95)$.

To explore which aspects of the debriefing meeting the interviewees discussed, the total number of details were separated into three categories: (1) About Agent 1; (2) about the interviewer and interview setting in the debriefing meeting; and (3) about the experimenter and Agent 2. The total details category consisted of the first two categories combined and was used in the hypotheses-testing analyses. The results for the two subcategories (details about Agent 1 and details about the interviewer and interview setting) were explored and are discussed in Appendix 2. The pattern of results was similar to that of the total details variable. The third detail category serves as a manipulation check and was not included in the total details variable.

One coder, experienced in coding complications, coded the complications in all transcripts. A complication is an occurrence that affects the storyteller and makes a situation more difficult. It is derived from the complications criterion used in Criteria-Based Content Analysis (CBCA) coding system (Criterion 7, Amado et al., 2016; Köhnken, 2004; Köhnken \& Steller, 1988), with one small difference. In CBCA complications are always unexpected events, whereas that is not necessarily the case in our coding system. Suppose someone says that he travelled from London to Miami but had a 48 hours stopover in New York for some shopping. That would count in our coding system as a complication (complicated itinerary), but not in the CBCA coding system, because it was not unexpected. However, the vast majority of complications we come across are unexpected, including the ones experienced by the participants in the present experiment. Again, in Phase 2 only new complications were 
coded. Examples of complications are: (a) "She stopped the interview at least once to blow her nose"; (b) "I forgot the exact wording of the code I meant to say to the agent"; (c) "I was confused about where to sit". A second coder coded a random sample of 21 transcripts. Interrater reliability between the two coders, using the two-way random effects model measuring consistency, was good (Single Measures, Intraclass correlation coefficient, ICC $=.79$ ).

\section{Results}

All statistical information is provided in Table 1. Apart from reporting the results for null-hypothesis significance testing (NHST) and the effect size (Cohen's $d$ ), we also report the results for equivalence testing to support any null findings demonstrating an absence of differences between truth tellers and lie tellers (see Lakens, Scheel, \& Isager, 2018). We decided that our smallest effect size of interest is 0.5 , and thus equivalence bounds ranged between -0.5 and 0.5 . Our decision was based on the fact that our research is applied and we were thus interested in observing a moderate to large effect size, and on previous lie detection research where medium to large effect sizes were found (see Vrij, Fisher, \& Blank, 2017).

\section{Manipulation Check}

Two ANOVAs with Veracity as the factor and the number of details provided about the experimenter and Agent 2 in Phases 1 and 2 as the dependent variables revealed two significant effects. Truth tellers reported more details than lie tellers in both phases. This reflects the instructions given to truth tellers and lie tellers. In interview 1 truth tellers were interviewed about the experimenter whereas lie tellers were interviewed about Agent 2. Truth tellers could openly recall in Interview 2 all that was discussed about the experimenter in Interview 1, whereas lie tellers had to avoid what was discussed about Agent 2. Although some lie tellers mentioned Agent 2 in the interview, none of them said that they had provided the interviewer in the debriefing meeting information about Agent 2. The manipulation was thus successful. 


\section{Questionnaire Variables}

In the questionnaire variables two significant findings emerged: Truth tellers reported to have paid more attention to the Model Statement and to have focussed more on the core details than lie tellers. Since paying attention to the Model Statement could have influenced the amount of information reported, we present the results with and without the effect of this variable as a covariate in the post Model Statement hypothesis-testing analyses. The mean scores showed that the participants were very motivated, had prepared themselves reasonably well and thought they were given sufficient time to prepare themselves. They thought there was reasonable rapport with the interviewer and found it neither likely nor unlikely that they would be asked to write a statement.

\section{Hypothesis-testing}

Two AN(C)OVAs were carried out with Veracity as the factor and the number of overall details (details about the interviewer and Agent 1 combined) in Phases 1 and 2 as the dependent variables. The details in Phase 2 relate to new details not mentioned in Phase 1. The amount of attention paid to the Model Statement was included as a covariate in the Phase 2 analysis but not in the Phase 1 analysis. We also ran $t$-tests (without the covariate) as shown in Table 1. All analyses revealed no significant effects. Equivalence testing for details in Phase 1 revealed that the data for truth tellers and lie tellers was statistically equivalent, and thus the effect was significantly smaller than the effect size of interest. Hypothesis 1 was therefore not supported.

Two AN(C)OVAs were carried with Veracity as the factor and the number of complications provided in Phases 1 and 2 as the dependent variables. The complications in Phase 2 relate to new complications not mentioned in Phase 1. The distribution of complications in Phases 1 and 2 are shown in Appendix 3. Again, the amount of attention paid to the Model Statement was included as a covariate in the Phase 2 analysis but not in the 
Phase 1 analysis. The analysis for Phase 2 revealed a significant effect. Truth tellers reported more new complications than lie tellers, and this effect had practical significance as equivalence testing showed that the null hypothesis was rejected. Therefore, Hypothesis 3 was supported. No difference between truth tellers and lie tellers emerged regarding complications in Phase 1. Hypothesis 2 was therefore not supported ${ }^{1}$.

We analysed cut-off scores for the variable that resulted in a significant effect: Number of new complications in Phase 2. The most straightforward decision rule would be 'A person who reports no new complications after the Model Statement is lying, whereas a person who reports at least one new complication after the Model Statement is telling the truth'. Running a cross-validated discriminant analysis (using the leave-one-out method) revealed that this decision rule resulted in the correct classification of $63.6 \%$ of truth tellers and $70.7 . \%$ of lie tellers, with an overall percentage of $67.1 \%, \Lambda=.87, \chi 2(1)=11.40, p=$ .001 , effect strength for sensitivity $(E S S)=34.2$.

\section{Discussion}

The truthful information lie tellers recalled provided evidence that they were hiding something: Lie tellers reported fewer complications than truth tellers, but only in the second recall, after the Model Statement was introduced (supporting Hypothesis 3 but not supporting Hypothesis 2). Based on this variable $67.1 \%$ of truth tellers and lie tellers were correctly classified, a high percentage given how challenging the task of detecting omissions through analysing speech content actually is. We manipulated the Model Statement using a 'withinsubjects' design: an initial free recall followed by exposure to Model Statement followed by a second free recall. Such a within-subjects design is recommended in the Model Statement literature (Vrij, Leal, \& Fisher, 2018), and it is particularly relevant for real-world investigations, where interviewers do not have the luxury of comparing groups of truth tellers to groups of lie tellers. An interviewee's response (e.g. number of complications) either needs 
to be compared to an absolute standard — which clearly is not possible, given the large differences across individuals — or through an after-versus-before a manipulation, the approach we used here. Since we did not manipulate the Model Statement factor (all interviewees were exposed to a Model Statement in Interview 2 after an initial recall), we cannot conclude that the Model Statement caused the complications effect. However, the finding is in alignment with the findings obtained in an experiment in which the Model Statement was systematically manipulated (Vrij et al., 2017).

Previous research has shown that truth tellers typically report more complications than lie tellers spontaneously in the first recall (Vrij et al., 2017; 2019) but we did not find that in the present experiment. The fact that lie tellers reported untruthful information in previous studies but not in the present experiment may explain that. Probably more work is required from investigators (such as using a Model Statement) to elicit verbal cues to deceit in an omission scenario than in other types of lie scenarios.

The amount of detail was not a diagnostic indicator of Veracity, which goes against the typical finding in deception research and does not support Hypothesis 1. Again, the fact that lie tellers reported untruthful information in previous studies but not in the present experiment may explain that. This does not necessarily mean that total details can never become a diagnostic indicator of detecting omission lies. Perhaps, similar to complications, an intervention is needed for total details to become a diagnostic cue. However, previous research has shown that the Model Statement intervention is not suitable for making total details a diagnostic indicator of Veracity, and in that respect, the Model Statement tool may have been an inappropriate intervention.

Note that the Model Statement was efficient in eliciting new details. The number of new details reported in Phase 2 exceeded the number of details reported in Phase 1. Although we, again, cannot conclude that the Model Statement caused the increase in details, this 
finding is in alignment with Model Statement research in which the Model Statement was systematically manipulated (Vrij et al., 2018).

The atypical findings that complications (in first recall) and total details (in both recalls) were not diagnostic indicators of veracity merits carrying out an experiment in which omissions are compared with another type of lie, for example outright lies, to determine whether the type of lie influenced the findings. That was not the aim of this experiment. Our goal in this first experiment examining verbal cues in lying through omissions was to examine whether such lies can be detected by speech content in the first place, something we could not guarantee when we started the research.

Compared to measuring details, measuring complications has one disadvantage. By definition, a verbal statement always contains details, but it does not always contain complications. This implies that the presence of many complications in a statement may indicate truthfulness, the opposite conclusion cannot be drawn and the absence of complications does not necessarily indicate deceit.

The sample size in the current experiment should have been sufficient for yielding high power. As we note in the pre-registration, a power analysis showed that recruiting at least 80 participants would be enough to yield a high power of $84 \%$. However, the confidence intervals of the effect sizes in Table 1 seem to be wide which reduced the precision of the effect size. It may be that a larger sample size was needed to obtain more precise effect sizes. Alternatively, the wide confidence intervals may mean that factors other than our manipulation may be affecting participants' self-reports and verbal responses. One factor may be individual differences, such as the extent to which an interviewee is talkative. Scholars suggest that within-subject measures are used to control for such differences (Nahari \& Vrij, 2015). Therefore, instead of comparing cues across different interviewees, the comparison can be made between cues within a single statement. As an example, deception researchers 
recently started examining the proportion of complications which is a within-subject measure that tests the ratio of the total number of complications in a single statement to the total number of complications, common knowledge details, and self-handicapping strategies in that statement (Vrij \& Leal, 2020). Future omission studies may examine similar withinsubject measures.

More work is required to obtain better insight into lying through omissions. Two lines of research can be derived from what we discussed in the previous paragraphs: Examining which intervention makes total details a diagnostic indicator of omissions and comparing lying through omissions with other types of lie. In addition, it is useful to test other deception scenarios than the one introduced in the present experiment. Only when similar findings are obtained across different deception scenarios can we generalise the research findings. If a different scenario is used, common knowledge details and self-handicapping strategies could be examined. To date, in a scenario where interviewees described a trip they allegedly made in the past twelve months, lie tellers reported more common knowledge details and more selfhandicapping strategies than truth tellers (Vrij \& Vrij, 2020). Describing a trip is arguably a scripted activity that enables lie tellers to use their common knowledge to fabricate a story (Vrij et al., 2017). The current scenario was an out of the ordinary event. In such events common knowledge details are less likely to occur (Sporer, 2016). In addition, the interview took place just after the event. Self-handicapping strategies are justifications why someone cannot remember some information. Such justifications are more difficult to create without raising suspicion when an event happened a short time ago (Vrij, Mann, Leal, Fisher, \& Deeb, 2020).

Measuring common knowledge details and self-handicapping strategies in combination with complications would create more certainty for practitioners when judging individual cases than just measuring complications. That is, a practitioner would be able to 
decide with more confidence that someone is lying if, apart from the absence of complications, common knowledge details and/or self-handicapping strategies did occur in a statement (Vrij, Leal, Jupe, \& Harvey, 2018).

In addition, all deception Model Statement studies to date used (slight adaptations of) the Model Statement introduced by Leal et al. (2015). ${ }^{2}$ It is thus unclear whether or not the pattern of results emerging from Model Statement research are specific to this particular Model Statement. Future research could examine this. Finally, it is worth examining how to distinguish between lie tellers who intentionally omit information with truth tellers who unintentionally omit information due to memory failure. Hopefully this article encourages other researchers to examine the important but neglected area of verbal indicators of omissions. 


\section{Author contributions}

The first and second authors designed the study, analysed the data and wrote the initial draft. The third and fifth authors ran the experiment, the fourth author helped with the statistical analyses and the sixth author commented on the initial draft.

\section{Acknowledgements}

This work was funded by the Centre for Research and Evidence on Security Threats (ESRC Award: ES/N009614/1) 


\section{References}

Amado, B. G., Arce, R., Fariña, F., \& Vilarino, M. (2016). Criteria-Based Content Analysis (CBCA) reality criteria in adults: A meta-analytic review. International Journal of Clinical and Health Psychology, 16, 201-210. Doi: 10.1016/j.ijchp.2016.01.002.

S.Ẹp. Brimbal, L., Dianiska, R. E., Swanner, J. K., \& Meissner, C. A. (2019). Enhancing cooperation and disclosure by manipulating affiliation and developing rapport in investigative interviews. Psychology, Public Policy, and Law, 25, 107-115. Doi`: 10.1037/law0000193

Buller, D. B., \& Burgoon, J. K. (1996). Interpersonal deception theory. Communication Theory, 6, 203-242. Doi: 10.1111/j.14682885.1996.tb00127.x.

DePaulo, B. M., Kashy, D. A., Kirkendol, S. E., Wyer, M. M., \& Epstein, J. A. (1996). Lying in everyday life. Journal of Personality and Social Psychology, 70, 979-995. Doi: org/10.1037/0022-3514.70.5.979

DePaulo, B. M., \& Kirkendol, S. E. (1989). The motivational impairment effect in the communication of deception. In J. C. Yuille (Ed.), Credibility assessment (pp. 51-70). Dordrecht, the Netherlands: Kluwer.

DePaulo, B. M., Lindsay, J. L., Malone, B. E., Muhlenbruck, L., Charlton, K., \& Cooper, H. (2003). Cues to deception. Psychological Bulletin, 129, 74-118. doi: 10.1037/00332909.129.1.74

Ewens, S., Vrij, A., Leal, S., Mann, S., Jo, E., Shaboltas, A., Ivanova, M., Granskaya, J., \& Houston, K. (2016). Using the model statement to elicit information and cues to deceit from native speakers, non-native speakers and those talking through an interpreter. Applied Cognitive Psychology, 30, 854-862. Doi: 10.1002/acp.3270 
Granhag, P.A. \& Hartwig, M. (2008). A new theoretical perspective on deception detection: On the psychology of instrumental mind-reading. Psychology, Crime \& Law, 14, 189-200. Doi: $10.1080 / 10683160701645181$

Granhag, P. A., \& Hartwig, M. (2015). The Strategic Use of Evidence (SUE) technique: A conceptual overview. In P. A. Granhag, A. Vrij, \& B. Verschuere (Eds.), Deception detection: Current challenges and new approaches (pp. 231-251). Chichester, England: Wiley.

Hartwig, M., Granhag, P. A., \& Strömwall, L. (2007). Guilty and innocent suspects’ strategies during police interrogations. Psychology, Crime, \& Law, 13, 213-227. Doi: $10.1080 / 10683160600750264$

Jundi, S., Vrij, A., Hope, L., Mann, S., \& Hillman, J. (2013). Establishing evidence through undercover and collective intelligence interviewing. Psychology, Public Policy, \& Law, 19, 297-306. Doi: 10.1037/a0033571

Köhnken, G. (2004). Statement Validity Analysis and the 'detection of the truth'. In P. A. Granhag \& L. A. Strömwall (Eds.), Deception detection in forensic contexts (pp. 41-63). Cambridge, England: Cambridge University Press.

Köhnken, G., \& Steller, M. (1988). The evaluation of the credibility of child witness statements in German procedural system. In G. Davies \& J. Drinkwater (Eds.), The child witness: Do the courts abuse children? (Issues in Criminological and Legal Psychology, no. 13) (pp. 37-45). Leicester, United Kingdom: British Psychological Society.

Lakens, D., Scheel, A. M., \& Isager, P. M. (2018). Equivalence testing for psychological research: A tutorial. Advances in Methods and Practices in Psychological Science, 1, 259-269. Doi: $10.1177 / 2515245918770963$ 
Leal, S., Vrij, A., Warmelink, L., Vernham, Z., \& Fisher, R. (2015). You cannot hide your telephone lies: Providing a model statement as an aid to detect deception in insurance telephone calls. Legal and Criminological Psychology, 20, 129-146. Doi: $10.1111 / 1 \mathrm{crp} .12017$

Leins, D., Fisher, R. P., \& Ross, S. J. (2013). Exploring liars' strategies for creating deceptive reports. Legal and Criminological Psychology, 18, 141-151. DOI: 10.1111/j.20448333.2011.02041.x

Metts, S. (1989). An exploratory investigation of deception in close relationships. Journal of Social and Personal Relationships, 6, 159-179. Doi: 10.1177/ 026540758900600202

Nahari, G. (2018). The applicability of the Verifiability Approach to the real world. In P. Rosenfeld (Ed.). Detecting concealed information and deception: Verbal, behavioral, and biological methods (pp. 329-350). San Diego, CA: Academic Press. Doi: 10.1016/B978-0-12-812729-2.00014-8.

Nahari, G., \& Vrij, A. (2015). Systematic errors (biases) in applying verbal lie detection tools: richness in detail as a test case. Crime Psychology Review, 1, 98-107. Doi: $10.1080 / 23744006.2016 .1158509$

Sporer, S. L. (2016). Deception and cognitive load: Expanding our horizon with a working memory model. Frontiers in Psychology: Hypothesis and Theory, 7, article 420. Doi: 10.3389/fpsyg.2016.00420.

Vallano, J., P. \& Schreiber Compo, N. (2011). A comfortable witness is a good witness: Rapport-building and susceptibility to mis-information in an investigative mock-crime interview. Applied Cognitive Psychology, 25, 960-970. Doi: 10.1002/acp.1789

Vrij, A. (2008). Detecting lies and deceit: Pitfalls and opportunities, second edition. Chichester: John Wiley and Sons. 
Vrij, A., Fisher, R. P., \& Blank, H. (2017). A cognitive approach to lie detection: A metaanalysis. Legal and Criminological Psychology, 22, 1-21. Doi: 10.1111/lcrp.12088

Vrij, A., Granhag, P.A., Mann, S. \& Leal, S. (2011). Outsmarting the liars: Towards a cognitive lie detection approach. Current Directions in Psychological Science, 20, 28-32. Doi: $10.1177 / 0963721410391245$

Vrij, A., \& Leal, S. (2020). Proportion of complications in interpreters-absent and interpreterpresent interviews. Psychiatry, Psychology and Law. Doi: $10.1080 / 13218719.2019 .17051$

Vrij, A., Leal, S., Deeb, H., Chan, S., Khader, M., Chai, W., \& Chin, J. (2019). Lying about flying: The efficacy of the Information Protocol and Model Statement for detecting deceit. Applied Cognitive Psychology, 34, 241-255. Doi: 10.1002/acp.3614

Vrij, A., Leal, S., \& Fisher, R. P. (2018). Verbal deception and the Model Statement as a lie detection tool. Frontiers in Psychiatry, section Forensic Psychiatry, 9, 492. Doi: $10.3389 /$ fpsyt.2018.00492

Vrij, A., Leal, S., Fisher, R. P., Mann, S., Deeb, H., Jo, E., Castro Campos, C., \& Hamzeh, S. (2020). The efficacy of using countermeasures in a Model Statement interview. European Journal of Psychology Applied to Legal Context, 12, 23-34. Doi: 10.5093/ejpalc2020a3

Vrij, A., Leal, S., Jupe, L., \& Harvey, A. (2018). Within-subjects verbal lie detection measures: A comparison between total detail and proportion of complications. Legal and Criminological Psychology, 23, 265-279. Doi:10.1111/lcrp.12126

Vrij, A., Leal, S., Mann, S., Dalton, G. Jo, E., Shaboltas, A., Khaleeva, M., Granskaya, J., \& Houston, K. (2017). Using the Model Statement to elicit information and cues to deceit in interpreter-based interviews. Acta Psychologica, 177, 44-53. Doi: 10.1016/j.actpsy.2017.04.011 
Vrij, A., Mann, S., Fisher, R., Leal, S., Milne, B., \& Bull, R. (2008). Increasing cognitive load to facilitate lie detection: The benefit of recalling an event in reverse order. Law and Human Behavior, 32, 253-265. Doi: 10.1007/s 10979-007-9103-y

Vrij, A., Mann, S., Jundi, S., Hillman, J. \& Hope, L. (2014). Detection of concealment in an information-gathering interview. Applied Cognitive Psychology, 28, 860-866, Doi: 10.1002/acp.305.

Vrij, A., Mann, S., Leal, S., Fisher, R. P., \& Deeb, H. (2020). Sketching while narrating as a tool to detect deceit. Applied Cognitive Psychology, 34, 628-642.Doi: 10.1002/acp.3646

Vrij, A., \& Vrij, S. (2020). Complications travel: A cross-cultural comparison of the proportion of complication as a verbal cue to deceit. Journal of Investigative Psychology and Offender Profiling Doi: 10.1002/jip.1538 
Table 1

Manipulation Checks, Questionnaire Variables and Details and Complications as a Function of Veracity

\begin{tabular}{|c|c|c|c|c|c|c|c|c|c|c|c|c|c|}
\hline & \multicolumn{3}{|c|}{ Truth } & \multicolumn{3}{|c|}{ Lie } & \multicolumn{4}{|c|}{ NHST } & \multirow[b]{2}{*}{$d$} & \multicolumn{2}{|c|}{$\begin{array}{l}\text { Equivalence } \\
\text { testing }\end{array}$} \\
\hline & $\mathrm{M}$ & (SD) & $95 \% \mathrm{CI}$ & $\mathrm{M}$ & (SD) & $95 \% \mathrm{CI}$ & $F$ & $p$ & $t$ & $p$ & & $t$ & $p$ \\
\hline \multicolumn{14}{|l|}{ Manipulation checks } \\
\hline Phase 1: Details about experimenter /agent 2 & 11.41 & (11.88) & $08.81,14.11$ & 02.17 & $(04.06)$ & $-0.63,04.97$ & 22.34 & $<.001$ & 4.86 & $<.001$ & $1.03(0.56,1.46)$ & 2.53 & .993 \\
\hline $\begin{array}{l}\text { Phase 2: New details about experimenter } \\
\text { /agent } 2\end{array}$ & 10.02 & $(15.57)$ & $06.65,13.40$ & 00.71 & $(01.60)$ & $-2.79,04.21$ & 14.53 & $<.001$ & 3.95 & $<.001$ & $0.83(0.37,1.26)$ & 1.60 & .942 \\
\hline \multicolumn{14}{|l|}{ Questionnaire variables } \\
\hline Motivation & 6.00 & $(1.08)$ & $05.70,06.30$ & 5.88 & $(0.93)$ & $05.66,06.19$ & 00.31 & .579 & 0.56 & .579 & $0.12(-.31,0.54)$ & 1.76 & .041 \\
\hline Preparation-thoroughness & 4.85 & $(1.16)$ & $04.51,05.19$ & 4.46 & $(1.13)$ & $04.10,04.81$ & 02.52 & .117 & 1.59 & .117 & $0.35(-.08,0.77)$ & 0.70 & .245 \\
\hline Preparation-time & 5.68 & $(1.38)$ & $05.29,06.08$ & 5.39 & $(1.24)$ & 04.98 .05 .80 & 01.05 & .310 & 1.02 & .310 & $0.22(-.21,0.64)$ & 1.29 & .101 \\
\hline Rapport & 4.94 & $(1.09)$ & $04.63,05.25$ & 4.75 & $(1.00)$ & $04.43,05.08$ & 00.67 & .417 & 0.82 & .417 & $0.18(-.25,0.60)$ & 1.47 & .073 \\
\hline Likelihood of writing statement & 3.55 & $(1.58)$ & $03.03,04.06$ & 4.02 & $(1.84)$ & $03.49,04.56$ & 01.67 & .200 & 1.29 & .200 & $0.27(-.16,0.70)$ & 1.04 & .151 \\
\hline Paying attention to Model Statement & 5.45 & $(1.42)$ & $04.99,05.92$ & 4.71 & $(1.71)$ & $04.22,05.19$ & 04.84 & .031 & 2.20 & .031 & $0.47(0.03,0.90)$ & 0.13 & .447 \\
\hline Focussing on the core & 5.50 & $(1.61)$ & $05.02,05.98$ & 4.56 & $(1.57)$ & $04.07,05.05$ & 07.43 & .008 & 2.73 & .008 & $0.59(0.15,1.02)$ & 0.42 & .662 \\
\hline \multicolumn{14}{|l|}{ Phase 1 (pre-Model Statement) } \\
\hline Details (overall) & 29.91 & $(16.06)$ & $23.66,36.52$ & 29.05 & $(25.53)$ & $22.48,35.62$ & 00.04 & .852 & 0.19 & .852 & $0.04(-.39,0.47)$ & 2.10 & .020 \\
\hline Complications & 00.55 & $(00.90)$ & $00.32,00.77$ & 00.29 & $(00.56)$ & $00.06,00.53$ & 02.38 & .127 & 1.57 & .122 & $0.34(-.09,0.77)$ & 0.71 & .240 \\
\hline \multicolumn{14}{|l|}{ Phase 2 (post-Model Statement) } \\
\hline New details (overall) & 40.50 & $(24.68)$ & $33.15,47.04$ & 34.54 & $(20.50)$ & $27.77,42.17$ & 01.01 & .318 & 1.21 & .231 & $0.26(-.17,0.69)$ & 1.10 & .138 \\
\hline New complications & 01.30 & $(01.21)$ & $00.96,01.61$ & 00.49 & $(00.87)$ & $00.16,00.84$ & 10.89 & .001 & 3.55 & .001 & $0.76(0.31,1.19)$ & 1.25 & .892 \\
\hline
\end{tabular}

Note. The questionnaire variables are measured on 7-point scales, ranging from [1] to [7]. The $F$-tests reported for Phase 2 include the effects of the covariate 'paying attention to Model Statement'. NHST = Null-hypothesis significance testing. 


\section{APPENDIX 1}

\section{Briefing about the mission and debriefing meeting}

The experimenter told participants to imagine that they were a secret agent for the government. They were instructed to deliver a package that contains classified information about a suspected terrorist cell to an agent (Agent 1). Since there were suspicions that Agent 1 is not providing accurate information regarding this intelligence further down the chain, participants should therefore also deliver a photocopy of the material to a second agent (Agent 2) after delivering the original copy to Agent 1 . They were told that it is vital that Agent 1 does not know that they are delivering a photocopy to Agent 2. Participants were then told that after their mission they would be debriefed in a debriefing meeting in which they should provide all the correct information about their mission.

The participants were then given detailed instructions about their mission and sent on their mission. After returning, the debriefing meeting took place.

\section{Interview 1: The debriefing meeting about the mission}

To ascertain that in the debriefing meeting some complications would occur, three disruptions were included which would make the interviewee to stop talking: (1) the interviewer's pen did not work; (2) an alarm goes off on the interviewer's phone; and (3) the interviewer is searching for a tissue.

All interviewees were asked four questions about Agent 1. They were asked in as much detail as possible to describe: Agent 1; the location where the delivery took place; details about the exchange; and details about the package. Some participants ( $n$ $=41$ ) were then asked the same four questions about Agent 2, whereas the remaining participants $(n=44)$ were asked these four questions about the experimenter 
(appearance, where they met the experimenter, how the experimenter contacted them and how they received the package).

After the debriefing meeting the participants were sent back to the experimenter.

\section{Briefing about the interview regarding the debriefing meeting}

The experimenter informed the participants that there are a number of levels of intelligence officials working on the mission they took part in. They would now be interviewed by an official who is specifically interested in the contents of that debriefing meeting. Participants were told that the interviewer in the next interview is aware of the details of the mission, but not aware of what was discussed about the mission in the debriefing meeting.

Participants were then told that the instruction to provide information in the debriefing meeting (Interview 1) about delivering the package also to Agent 2 was wrong. Participants were then asked whether Agent 2 was discussed in the debriefing meeting. Those who said that this was the case $(n=41)$, were then told that it is vital that they would not reveal in the next interview that they discussed Agent 2. They were further told to be entirely truthful about the other elements of the debriefing meeting. These participants thus became lie tellers in the experiment and were asked to omit information in the next interview about Agent 2. Those who said they were not asked about Agent 2 in the debriefing meeting $(n=44)$ were instructed to be entirely truthful in the next interview and thus became the truth tellers in the experiment.

To motivate participants to perform well during the interview, they were told that if the interviewer believes that they did truthfully recall in the interview everything that happened in their debriefing meeting, they would receive one entry 
into a draw to win up to $£ 150$. If the interviewer would not believe them, they would not be entered in the draw and would be asked to write a statement about the debriefing meeting instead.

Participants were then offered time to prepare for the interview. Once participants said that they were ready to be interviewed they completed the preinterview questionnaire before being taken to the interview room for their interview.

\section{Pre-interview Questionnaire}

In the pre-interview questionnaire, participants rated their thoroughness of preparation via three items: (1) shallow to (7) thorough; (1) insufficient to (7) sufficient; and (1) poor to (7) good. The answers to the three questions were averaged (Cronbach's alpha $=.72)$ and the variable is called 'preparation thoroughness'. Participants were also asked whether they thought they were given enough time to prepare themselves with the following question: 'Do you think the amount of time you were given to prepare was: (1) insufficient to (7) sufficient. Finally, participants were asked how motivated they were to perform well during the interview on a 7point scale ranging from (1) not at all motivated to (7) very motivated.

\section{Interview 2: The interview about the debriefing meeting}

Participants were taken to the same interview room where they did Interview 1. However, they were interviewed by a different interviewer. The interviewer introduced the interview as follows: I understand that you were recently sent on a mission to deliver a package to one agent (Agent 1) and then also to deliver a copy of this to another agent (Agent 2) and that after completing this mission you were debriefed regarding the details. In our section of the organisation we are particularly concerned with what you were asked and what exactly you revealed in that debriefing meeting - do you understand? 
Participants were then asked to describe in as much detail as possible everything that happened during the debriefing meeting from the moment they entered the interview room to the moment they left the room. After this Phase 1 of the interview the Model Statement was introduced as follows: "I would now like you to tell me again what happened, but before doing so, I would like to play you an example of how many details I would like you to include in your response. The example I will play is a so called 'Model Statement' as it gives you an idea of a detailed response to a question. After listening to the example, I would like you to be that detailed in your response, ok?"

The interviewer then played the audiotaped Model Statement used by Leal et al. (2015). It was a 1.30 minutes long detailed account of someone attending a Formula 2 motor racing event. The account was a spontaneous, unscripted, recall of an event truly experienced by the person. It included one complication. The person said that when the racing cars came out he had to move to one side to avoid being run over.

After the Model Statement the participants were asked to once more tell everything that happened during the debrief meeting but this time to bear in mind the amount of detail they heard in the Model Statement. After this Phase 2 of the interview the participants were sent back to the experimenter to complete the postinterview questionnaire.

Only Interview 2 is of interest in the experiment. The interviews were transcribed and coded. The information provided about the interview (including interviewer and interview setting) and Agent 1 was used for the hypothesis-testing analyses; the information provided about the experimenter and Agent 2 served as a manipulation check. 


\section{Post-interview questionnaire}

We measured rapport with the interviewer, because rapport is an important motivator for a productive interview (Brimbal, Dianiska, Swanner, \& Meissner, 2019). It was measured via the nine-item Interaction Questionnaire (Vallano \& Schreiber Compo, 2011). Participants rated the interviewer on nine characteristics such as smooth, bored, engrossed and involved, using 7-point scales ranging from [1] not at all to [7] extremely (Cronbach's alpha $=.85$ ). Participants also rated what they thought the likelihood was that they would be asked to write a statement using a 7point scale from (1) not at all likely to (7) very likely. They finally rated the extent to which they paid attention to the content of the Model Statement and the extent to which they focused on the core (defined as very relevant) details of the mission using a 7-point scale from (1) not at all to (7) totally. 
APPENDIX 2

Table 2

Details and Complications as a Function of Veracity

\begin{tabular}{|c|c|c|c|c|c|c|c|c|c|c|c|}
\hline & \multicolumn{3}{|c|}{ Truth } & \multicolumn{3}{|c|}{ Lie } & \multirow[t]{2}{*}{$F$} & \multirow[t]{2}{*}{$p$} & \multirow[t]{2}{*}{$t$} & \multirow[t]{2}{*}{$p$} & \multirow[t]{2}{*}{$d$} \\
\hline & $M$ & $(S D)$ & $95 \% \mathrm{CI}$ & $M$ & $(S D)$ & $95 \% \mathrm{CI}$ & & & & & \\
\hline \multicolumn{12}{|c|}{ Phase 1 (pre-Model Statement) } \\
\hline Details-interview & 09.30 & $(06.82)$ & $07.11,11.48$ & 07.85 & $(07.78)$ & $05.59,10.12$ & 00.83 & .365 & 0.91 & .365 & $0.20(-.23,0.62)$ \\
\hline Details-Agent 1 & 20.61 & $(14.48)$ & $15.35,25.88$ & 21.20 & $(20.36)$ & $15.74,26.65$ & 00.02 & .879 & 0.15 & .879 & $0.03(-.39,0.46)$ \\
\hline \multicolumn{12}{|c|}{ Phase 2 (post-Model Statement) } \\
\hline New details-interview & 18.64 & $(11.49)$ & $15.06,22.11$ & 12.88 & $(11.58)$ & $09.28,16.59$ & 04.76 & .032 & 2.30 & .024 & $0.50(0.06,0.92)$ \\
\hline New details-Agent 1 & 21.86 & $(22.50)$ & $15.49,27.54$ & 21.66 & $(16.28)$ & $15.79,28.28$ & 00.01 & .906 & 0.05 & .962 & $0.01(-.42,0.44)$ \\
\hline
\end{tabular}


We further explored the details effect by examining the number of details reported about each of the two subcategories of details: Details about the interview (including interviewer and interview setting) and details about Agent 1. Four AN(C)OVAs were conducted with Veracity as factor and the number of details about the interview and Agent 1 provided in Phases 1 and 2 as dependent variables. The amount of attention paid to the Model Statement was included as a covariate in the Phase 2 analyses but not in the Phase 1 analyses. We also report the $t$-tests for all analyses. One significant effect emerged. Truth tellers provided in Phase 2 more details about the interview than lie tellers. Although the effect size for this effect was medium, the Bayes Factors only showed weak evidence for this effect. Regarding the other three effects, the $d$ scores and $\mathrm{BF}_{10}$ factors suggest strong evidence for the absence of a Veracity effect for all three variables. 


\section{APPENDIX 3}

Figure 1

Distribution of Complications in Phase 1 of Interview 2 as a Function of Veracity

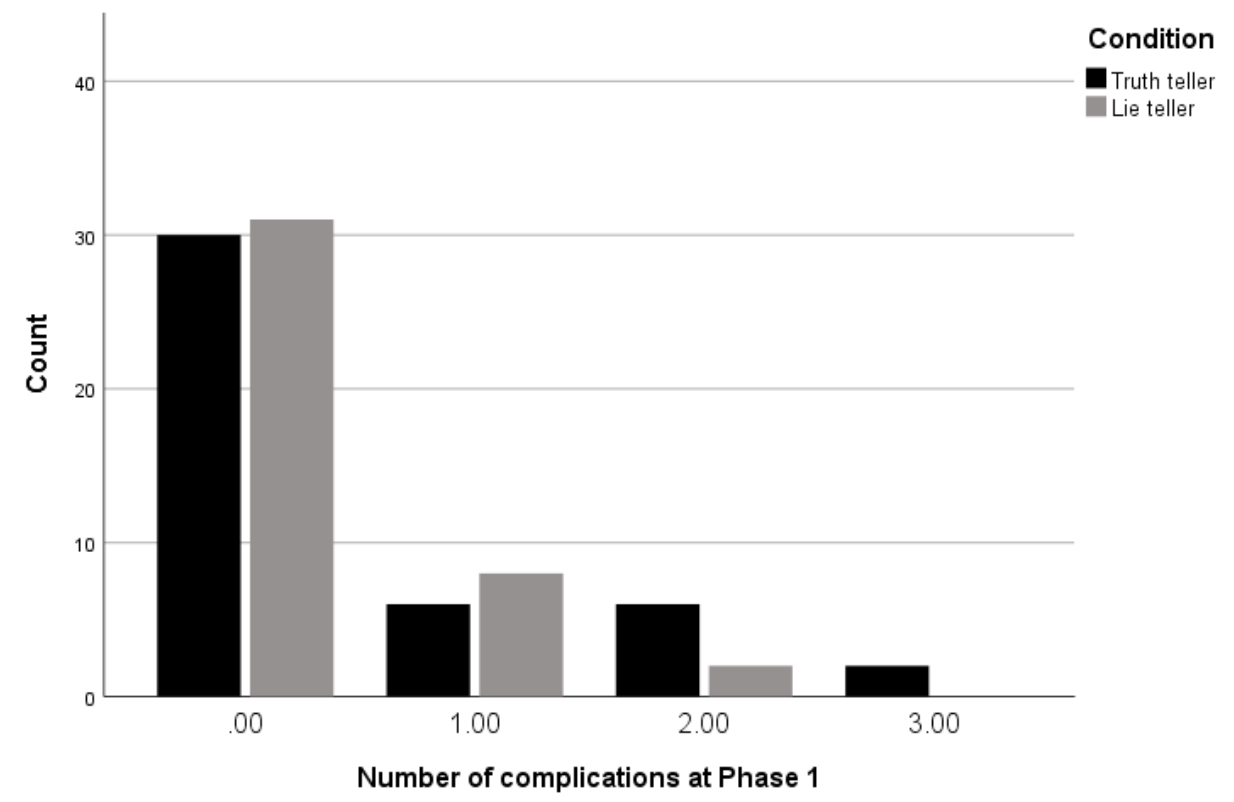




\section{Figure 2}

Distribution of New Complications in Phase 2 of Interview 2 as a Function of Veracity

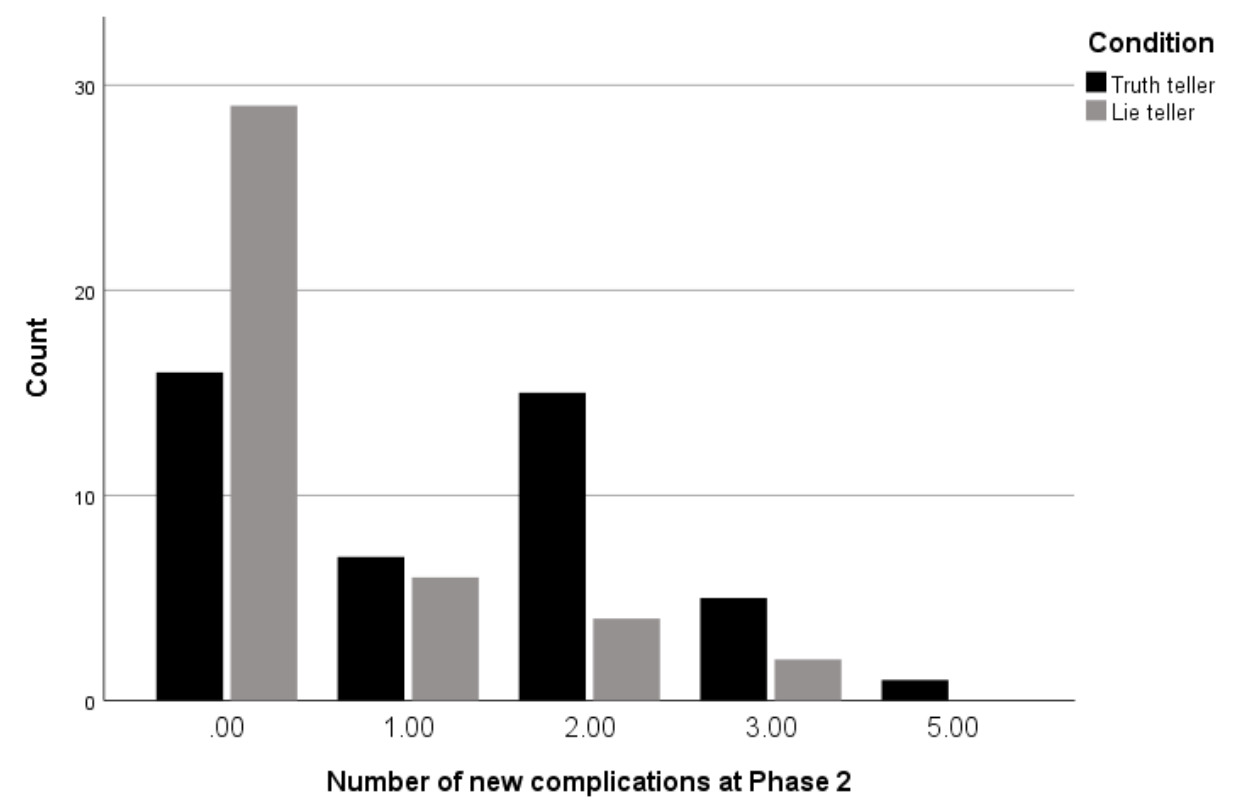

\footnotetext{
${ }^{1}$ We ran Kruskal-Wallis H non-parametric tests for details and complications in Phases 1 and 2, and the same results emerged: Only new complications reported in Phase 2 revealed a significant effect $(p=.001)$.

${ }^{2}$ The exception is Ewens et al. (2016) who used two Model Statements: The Leal et al. (2015) Model Statement and a second one. No differences in findings emerged between the two Model Statements.
} 